\title{
6 Sport (and Shadowplay)
}

\author{
The doer with desire \\ Hot for the prize of vainglory \\ Brutal, greedy and foul, \\ In triumph too quick to rejoice \\ In failure despairing \\ The Bhagavad Gita
}

It is to the Duke of Wellington, the one who accepted Napoleon's resignation at Waterloo, that the likely apocryphal, but famous, saying is attributed, that the battle of Waterloo was actually won on the playing fields of Eton: an overstatement, by any count (I've seen the playing fields, and the players, of Eton - they're nothing to write home about). On the other hand, our idea of behavioral adequacy in sports is probably not too far apart from our understanding of competition more generally. As already indicated, the real homespun ideology of America is social Darwinism; the Heritage Foundation, Rush Limbaugh, and William Buckley only give a pedantic, and pretentious, twist to a fairly simple set of beliefs shared quite broadly. The first article of faith in market ideology is that of competition, conflict, and struggle, of each against all. As Hobbes put it, succinctly, given this undeclared War, the life of man is solitary, nasty, brutish and short; the fellow human being is competitor, obstacle, enemy and rival; he needs to be bested, beaten, run out of business. Do unto Others, runs the unspoken commandment, before others do unto you. Conviviality, co-respective consideration, camaraderie, co-operation, vanish in the face of these rank alienations; alliances are only temporary cartels to secure some mutual gain, to be abandoned as soon as individual avenues of further gain become available. The goal, quite simply, is limitless personal success, success made even sweeter with the knowledge that it is bought at the cost of a hundred failures - of others. Vince Lombardi, legendary Coach of the Green Bay Packers, said it for the system, summing up the American Creed in all things, when he said,' Winning isn't everything, it's the only thing'. Defeat is worse than death, because you have to live with it.

Winning is the only thing, the real thing; and it's not simply coming out ahead, irrespective of the outcomes of the also-rans. It's a zero-sum game, where victory is spiked, made headier, by the prostration of the fallen, measured by how far we've left the losers behind. Other cultures commiserate with losers, console them, comfort them; we bury them alive. Chivalry, generosity, honor, and sportsmanship, are all feudal codes with no echo in American life, either in private or in public life. Watching Americans at play is watching Americans at war; there is no true difference. Take the Barcelona Olympics (or even the recent one in London) and review the coverage; the Media treated the Games with the same intensity, and breathlessness, they brought to the coverage of the Gulf War; every event was a skirmish, a personal combat, a clash between America and the rest-of-the-world, a struggle between the red, white 
and blue, and the sorry crews who dared to compete against them. It viewed every medal as rightfully belonging to the US, usurped only by chicanery, fraud, or artifice, whenever some other nation walked off with them. A Chinese diver wins gold, and the announcer can barely conceal her disappointment - the gold should have been ours; our woman runner finishes fourth - the winners must all be up to something dark and Machiavellian, she mutters angrily, to the happy echoes of the eager interviewer. The exaggerated attention brought to American triumphs, coupled with the sour grapes brought to victories of non-Americans (the fact that puny little Cuba whipped us soundly at our vaunted national game, baseball, was all but neatly obscured in the jingoistic reporting) could only turn you off from the many brilliant personal performances of the individual athletes wrapped in the Stars and Stripes, as crowd sentiment at the Games clearly indicated.

Interestingly, though citizens of a megapower, Americans still, at heart, regard themselves as the new kids on the block, the Johnny-Come-Latelys, the Lilliputs, the Davids, of world competition, who must win everything, again and again, to prove they are a force to be reckoned with, a nation to be respected, a people to be given credit to. Deep in the dark heart of America is a dread, dire memory, and foreboding, that maybe, just maybe, they aren't really as good as they think they are; it's a profound inferiority complex, possibly born of their own initial, humble, beginnings when they were scorned as a nation made up of the refuse of others, always feeling a little gauche, a little insecure, a little ill at ease, with the high pretensions of aristocratic Europe. Sure, they can buy all the crowned heads of Europe now, but they can't really cut it in any other higher, less material, sphere; it's a form of resentment, a sort of 'third-world' consciousness, that has never quite disappeared since they led one of the first great revolts against colonialism. Indeed, the upper class Boston Brahmin, of State Department repute, is usually a Europhile, a worshipper of aristocracy, a lover of the Old world - to the detriment of the more hokey, parochial, and populist institutions of his own country, which he is usually only too happy to leave behind with a shudder.

And so the media got behind its athletes, dropping the Losers fast, and staying with the Winners, right down to the last note of the national anthem played at the victory stands, the Americans stood tall with hands clenched against their hearts, like christians who had just slain devouring lions, or Davids just come from felling Goliaths. Gold, silver and bronze, the eyes of the media cameras never looked past the medal winners, the also-rans, the unheroes, the losers; barring cases involving fallen American medal prospects, the cameras searched only for gold in every event, for in the Olympic World-War, the real war in pantomime, 'winning isn't everything, it's the only thing'. And the Nike-Reebok endorsing, basketball 'Dream Team' (brought in every hour or so in the coverage, as glowing indemnity against other American losses), powered by their distance, physical, financial, and ideological, from every one they played against (their crushing defeat at the 2004 Greek Olympics a species but of karmic pedagogy), with non-stop media hype pumping up their adrenalin, cut 
a swathe through the Games all their own: matchless performance ability matched only by their matchless, all-American, egotistic, chauvinism, treating all other teams and players as so much offal. One of them said it for all of them, on the Olympic TV Station, when he said, without the slightest hesitation, that they were in it not for sport, nor sportsmanship, nor even patriotism: it's marketing, he said, it's money, that's what it's all about. And this, because he was being asked why he had deliberately elbowed a member of another team in the stomach during play. He could just as easily have quoted Vince Lombardi again, who said, 'to play the game you must have fire in you, and there is nothing that stokes fire like hate'. The 'Dream Team' was not about romance, as the name might misleadingly suggest; it was about hate, assertion, and supremacy - professional players for the most part, earning six-figures and above, they were the entrepreneur-businessmen of basketball, on a business trip to Barcelona. Few teams, other than some from previous Olympics, from the erstwhile Eastern Bloc, missed the spirit of the Olympics (not as it is, of course - Baron Pierre de Coubertin, French patriot, founded the Olympics only as a boost to the military prowess of French youth, in the aftermath of France's defeat at the hands of Germany in 1871 - but as it might be) more spectacularly, in being precisely all-American, jingoistic, all-grasping, in their attitudes.

Media dislike for foreigners who win was never stronger than in the case of the tv lynching of Ilie Nastase ('Nasty', as the media named him, in their hospitable way), in the Seventies; the Cold War was hot, and here was an Iron Curtain Romanian who was cleaning out the goldplate, match after match, to the disgust of the local and national Sponsors of prize money; worse, he was doing it with verve, elan, style, and a personalized statement of fearlessness, bravado, and spirit, that stung the American ego no end. He was winning, and cocking his snook at them, at America, in America; this could not be tolerated, and sportscasters went out of their way to hang him with insult, invective, and satire. It didn't work; Nastase had the temperament usually idealized (or vilified) as Latin; he was an individual, not a bureaucratically cloned robot, like the clean-cut, professional, American athlete, careful to cultivate a (usually phony) 'good-boy' image - saying the trite, but right, thing as and when required. He was passionate, had a temper, and a temperament, and he gave expression to his feelings openly, profusely, and without holding back. He was an incomparable stylist, playing his game like a ballet star, and yet with the power and grace of a tiger; indeed, I have not seen such beautiful moves on a tennis court since his eclipse. But he was not a good corporate model of compliance and control; and so the attacks on him, open and blatant, sometimes, to the point of incitement to violence: one announcer, in a game in Houston, stopped short, but only by a hair's breadth, of openly calling on any redblooded, six-foot, Texan to step on to the court and clobber him. For all that, Nastase was a hero, a comic, and a crowd pleaser, and the Media had to settle for stark, unrequited hate; indeed, compare the all too human passion of Nastase, to the spoilt, ugly, violent, antics of a MacEnroe, and you realize there are good and bad, attractive and unattractive, indeed even loathsome, forms of deviant behavior. 
Violence, said H. Rap Brown, is as American as cherry pie; and the domain of organized, commercial sport is seasonal evidence of the reality of that statement: football, ice hockey, boxing and box lacrosse (Collision sports, as has been justly remarked, and not 'contact' sports as usually described) are the modern equivalents of medieval jousting and the gladiatorial contests of Antiquity, both fans and contestants equally rabid and blood-thirsty, licensing the public muggings, the gang-warfare, that can literally litter the arena with blood and gore. It is social Darwinism again, the order of nature recreated in society; tension is the structure of the universe - and violence and competition natural laws that must be obeyed. Sports simply teach Americans the facts of life in simile and metaphor; and so the weekend simply continues the workweek, not as easeful antidote to its exactions, but as a restless, dutiful extension of it. Given the aggressions of social and business life, sports appear no more untidy, unseemly, or violent, than the hostile take-over, the sneak trade attack, or the quick commercial killing; but, where the hunting - and killing - of peaceful animals is a licensed 'sport', too, what more can we expect?

America is only the scrofulously developed form of European Mercantile social norms, mores, and values, with violence and aggression merely the accompaniments to expansion and growth (and the philosophies of limitless expansionism, limitless growth), destructive and exploitative both of Other cultures, peoples, and nature, and inflicting both genocide and ecocide in its blind wake. The all-conquering British found the social customs of Buddhist Burma far too 'feminine', lacking aggression, lacking covetousness; in a decade, they set about changing the legal system and instituting rewards and punishments to swing things around to more masculine traits one part of the change being to eliminate the legal independence of women, and their properties, and make them totally the dependent 'charges' of their husbands, sons, and brothers. The British Administrator, proud Patriarch of Empire, was convinced this would put power right where it should belong (and women where they belonged): in the hands of the aggressive, rapacious New Man of Burma - another progressive 'gift' of the English to the Asians they plundered, pillaged, and ravished, for some four hundred years (of course the Sun never set on the British Empire; even God wasn't ready to trust the Englishman in the dark).

Almost as if poetic justice were being acted out, for the explicit purpose of redressing history, I witnessed, as a youngster, an English/Indo-Laotian encounter of a kind I shall never forget. It took place in the British 'public' school I attended in the Himalayas, which attracted a good many students from south-east Asia, and from around the world, one of them being a mild-mannered prince, a lotus-eater, from the Royal House of Laos. The school itself, modelled after its English template, like so many of its kind, was a colonial institution teaching Indians European values and, simultaneously, distrust of all things Indian (a great success, measured by the sybaritic, Europhilic elites that it eventually helped produce); and we went through an All-English Curriculum (as if it were Eton or Harrow, and not a school in the Himalayas - studying Shakespeare to the exclusion of Kalidasa, Adam Smith to the omission 
of Kautilya, and the Iliad, to the avoidance of the Mahabharata, and so on), which included, amongst other things, the martial 'sport' of boxing. It so happened that the Laotian prince, being devoutly Buddhist, held the savage art in abhorrence and refused to engage in it. Our British physical ed. Instructor (not a Colonel Blimp, but a sort of a Sergeant-Major Blimp) was equally adamant that the bleeding Buddhist had to be taught the civilized arts of England, and forcibly marched the crying student prince into the ring. The boy fell to his knees, and locked his hands in prayer, asking to be forgiven the sin being demanded of him; he was forced to stand up, and, just to get him rallied, the burly Englishman (with about a 75 pound weight advantage in his favour) threw a flurry of punches at him, taunting, goading him, to 'be a man, and fight'. The prince stood motionless, expressionless, in meditation, taking blows, without flinching, but not returning any. All the while the Englishman kept up his barrage, verbal and physical, as we all stood around in the gym, horrified, hearts bleeding for our poor fellow-student; and then, all but unnoticed, the prince, with all but unseeing eyes, made one, clean move and his tormentor was down on the floor, out cold, jaw broken in three places. That, for me, for I was still young, was a Script written by an Irate God; Burma, that day, had been avenged.

Sports could be a matter of play, of pacific tests of endurance, agility, strength and speed, a matter of enjoyment, an expression of life, affirming human fraternity, individual aspiration, and social regard. Instead, it is turned into another alien form of market domination of social life: into labor, into work, into another route to employment, another form of struggle, conflict, tension, and desperate competition, yielding a wage to the athlete-worker, a profit to his/her owner/employer and passive, vicarious enjoyment to the spectator/consumer. For a few, of working class or minority origins, it has meant an otherwise unreachable plateau of wealth, status and public recognition, though extremely volatile and transient; for the many others who tried but failed, but another source of bitterness, frustration, and anger. For the average American, the true connections are never drawn; all those who roundly, if somewhat routinely, and ritually, condemn the violence in sports (it's hip to protest such things) are quite compliant with its total subordination, its prostitution to business, and to marketization, quite unclear - or heedless - as to the powerful links, the symbiosis, between the two. And, finally, we fail to see that the violence and the business motive are all securely intertwined in that unwholesome brew called the American Way, which dominates all our institutions, at work and play, with staggering ferocity; the aggression being not just 'out there', in field and ring, but within us, at the core of our very being.

Class division, racism, and corporatism, are as common to sports as they are in society more generally, the various sports themselves bearing a definable race/class/ gender connotation. Effective desegregation of baseball, basketball and football are exclusively post-1945 phenomena, African-Americans moving essentially from zero participation to overwhelming domination in just a few decades (inclusion in the games, is of course, no warrant for entry into off-field socialising; there, segregation 
still holds its ugly sway). And class provides its own separations: in the main, baseball and basketball are blue-collar/black-man sports; tennis and golf, white-collar/ white man entertainment. A basketball player is more likely black than white, a tennis player more likely white than black (despite 'Tiger' Woods, golf remains overwhelmingly white). The American athlete, on average, is black; the coach, preponderantly, is white. Just think of the US Olympic team without Africans(and I heard a media announcer say, without a blush, that Africans weren't doing so well in the Olympics!); yeah, blacks are real Americans to be cheered when they win medals for us in the international spotlight, or serve as cannon fodder in our military excursions the world over, but it's all very different when they're being ordinary Rodney Kings out on the streets of America, or trying to buy a home in white suburbs). In times gone by, to give raw remembrance its due, even lynching was an organized sport, a total entertainment, complete with hawkers, peddlers, and vendors. And so the great, fractured soul of America lives on in its playing fields, undisturbed by either sentiment, sensitivity, or values. As for corporatism, the very organization of the typical sport is corporate; the athlete-worker, the coach-foreman, the manager-manager, the owner-boss, and the fan-consumer are quite the familiar units of any business; and it is quite a big business (\$414 Billion in 2012) - spectator sports generated, in mere ticket sales alone, \$4.8 Billion in 1990, \$7.4 Billion in 1995, \$11.5 Billion in 2000, \$13.6 Billion in 2002, and $\$ 22.4$ Billion, in 2012 - involving concessions, television rights, endorsements, sponsorships, gambling, and the like; ahead, incidentally, of industries as mighty as hotels, air transport, and television. Exempted from anti-trust laws, the sports monopolies handily live off state subsidies, tax-payers footing the bills for the giant superstadiums used by private enterprise (the tax write-off game being another sport, in its own right, profits usually being passed off as capital gains rather than as income). As for sexism, the collision sports are all about the rat-race for the prize of masculinity making for both male bonding and male rivalry; the roles assigned to women, in such a raw pageant of machismo, can possibly be guessed at, when we learn that one of major league baseball's favorite, off-the-record, pastimes (between-before-during games) is 'beaver shooting', undertaken from atop hotel rooftops to below-stadium seating.

We are a deeply narcissist, physical culture, perhaps more so than any I know of; where else would football players be eagerly sought after as ideal salespeople? All our preliminary evaluations are physical; our silent, unspoken, but deeply competitive, assessments, start first with instinctive appraisals of comparative physiques, sizes and shapes, though it doesn't stop there; looks are everything, at least for starters. The fitness kick is not merely a wholesome wish to prolong life, and cultivate good health, but is pre-eminently cosmetic: to look good, feel young, be taken as attractive, shapely, desirable. It is, like anorexia at one extreme, a disorder, a social neurosis, a paranoia, a pathology, that keeps us jogging, running, biking, dieting, and spaing, way beyond the normal needs of ordinary fitness, in defiance of normal bodily rhythms, cycles, and progressions. I go to a neighborhood spa about once a week, enough to see the frustrations boil over; a girl, on borderline anorexia, weeps at the 
end of her routine almost every time, looking to the mirror, looking to herself; and I wish I could see what she sees in there that hurts her so to make her tear silently as she leaves, all but unnoticed.

The resulting misanthropy is painfully explicit; a visiting English woman journalist to New York writes a bitter letter to the editor about the wanton malevolence of the fitness freak, a male jogger, in Central Park, who ran straight into her, rather than yield an inch of the sidewalk, at a moment when her attention was elsewhere; it was the same with cyclists she complained, without an iota of civic sense, human regard, even simple manners: the message of the fitness fan to the ordinary mortal is - unlike you, I am working on self-improvement, you ordinary vermin, so out of my way before I run you down. And so, exercise designed to relax, and ease tension, turns into a treadmill - where we struggle against ourselves, the exercise machines, and others, to overachieve and outperform, recreating the very crises we are supposed to be hoping to balance out. Not the motions, nor the mechanisms, but our very motivations, that are deeply skewed, deeply corrupt, deeply self-destructive, just as much unhappiness leaving the spa, and like arenas, as about enters it.

It is emphatically a false, though popular, inference that the bitter, unyielding conflict in sports is a safety valve of harmless aggression, a great release for all the pent up accumulated frustrations, and tensions, of life and work; it is simply another forum for their expression, another avenue for their exercise, another arena for their employment: it does not reduce the potential for violence, it adds another domain to it. It is not true that the human body and the intellect respond positively, and creatively, prospering, growing, and maturing, with challenge, threat, and intimidation, as social Darwinist, capitalist ideology has it (just watch fans rioting, and players running amok, in the average ice-hockey game to see the absurdity of the argument); it is rather that minds, and motivations, get warped, misdirected, wasted, and perverted, in needlessly exaggerated competitive struggles. Sports and sporting events organized in the American way do not, cannot, sustain harmony, or solidarity, bringing people together as is sometimes imagined, in defiance of our individual, separate existence; but only pours added fuel to the burning rage, anger, and frustration, borne within. Sports do not compensate for the drudgery, the routine, the toils of life; they are a co-opted part of it.

It is not just that society and politics intrude into sport, as is obvious; the interchange runs both ways. Sport and sporting metaphors insinuate themselves into business, politics, sex and war; small wonder 'game theory' can be applied to all sectors - dream teams, winning strategies, power plays, existing in all domains. It's all a game: the corporate game, the political game, the social game, where we all take our chances, as at a table in Vegas. I play the stock market, you score with your girlfriend; life itself is a form of roulette, the spin of the wheel determining our failures, successes; and the world, the Great Casino stacked with risk, uncertainty and opportunity. You wait for your chance, then make your play; that's the name of the game. We are all gamblers; only the size of our stakes (and our winnings) helping to 
separate us. Some win, some lose, that's the breaks, that's the law of the table; so runs our ideology. We choose our tables, our games, our gambling strategies-the odds are the same for all comers. Nobel prize winning economist Paul Samuelson enshrines this feckless ideology into 'science', with the suggestion that we can all 'choose' to be either workers or capitalists, in the capitalist 'game', quite voluntarily; after all, all a worker has to do, to be a capitalist, is to simply 'hire capital'! And so, the Great Myths of Capitalism come to be consecrated in the general ideology veiling all our activities, at work and at play, from our own thinking selves.

The business of sport has transformed play into work, relaxation into struggle, leisure into labor; to reclaim sport as recreation, we need to alter the fundamentals of our social design (externally and internally), to reject acquisitiveness, to renounce aggression, to repeal covetousness, avarice, and greed, to abjure violence, anger, and hate. We need to reclaim our lives, our livelihoods, our rights, from the tyranny of alien markets and alien governments alike; we could seek the pacification of human existence, the gratification, not of our lowest, but of our highest needs. We could turn work itself into play; so life itself may be a form of creation and recreation of our social selves.

I remember stopping by a village near Milan, years ago, exhausted by day-long bus-riding, by a patch of green, where villagers, young adults, were exulting in Italy's favorite sport: soccer. They wore no uniforms, had no clear markings on the field, nor had even the minimum desiderata of goal-posts (stumps substituting for that frill); they were unkempt, they were ill-clothed, they were boys and girls, young men and women; and they were having the time of their lives. They threw themselves into the game with all their energies, chasing the ball like it were the last one left on earth, falling over each other, harrying each other, pushing, shoving, whistling, yelling, chivvying, arguing, and jostling; boy, were they loud, raucous and competitive! The makeshift 'referee' played a flute when not refereeing; the goalees, at either end, danced cartwheels and climbed goal posts, during temporary lulls; frequently they all jumped into a general scrimmage, not necessarily chasing a ball, including a couple of spectators too excited to stay out, screaming, shouting, laughing their heads off, collapsing finally in a big convulsion of helpless hysterics. When a goal was scored, the jubilation was indescribable; they hugged, danced, kissed, and sang, blew horns, running around the field like a wolfpack gone amok, swigging at bottles of beer, kicking at imaginary soccer balls, leaping high into the air. The other side hugged and kissed, too, but more sombrely; the goalee, a girl, reduced to tears, lying prostrate on the field with grief unbounded, momentarily inconsolable; and then they were all at it again, in all earnest, play resumed. It was not a soccer game, but a love-fest; and, for a full forty-five minutes, I watched these gala antics mesmerized, aching to be part of it, to play, to join in - where in all the world could so much fun be had? What sordid businessman could corrupt those virgin souls? What bullying coach could kill their spirit in meaningless drills? What hectoring referee would dare to intervene in their hugely lively, entirely democratic, squabbles over decisions? 
Where there is some unedited spontaneity left, there is still hope, there is still the possibility of life, the warranty of redemption. Mind you, Italy is a modern, capitalist economy, a member of NATO, an ex-fascist polity no less - and the youths disporting in the village green no doubt returned to a pitiless industrial drudgery the next morning, and the morning after; but, for that brief interlude, their recreation was not commodified, controlled, externalized, made chargeable. In many ways, in its social life, Italy has maintained continuities with its medieval, feudal past (good and bad); yet, in that little cameo of unregulated elation, in industrial Milan, is the nucleus of possibilities that lie within us all, waiting to be revived, explored, set free. 